\title{
PERTURBATION STRATEGY FOR SPLITTING OPERATOR METHOD TO SOLVE THE SET-VALUED VARIATIONAL INEQUALITIES
}

\author{
SALAHUDDIN
}

Abstract. In this paper, we suggest a new perturbation strategy for a splitting operator method for solving the set-valued variational inequalities with strongly monotone and compact mappings, under the mild condition, and prove the global convergence of the method. Also, we discuss the self-adaptive strategy and find the approximate solution of the set-valued variational inequality problems.

Mathematics subject classification (2010): 49J40, 47H09, 47J20, $54 \mathrm{H} 25$.

Keywords and phrases: Set-valued variational inequality problems, splitting operator methods, perturbation strategy, monotone mappings, Lipschitz continuous mapping, Hausdorff metric.

\section{REFERENCES}

[1] G. Stampacchia, Formes bilineaires coercitives sur les ensembles convexes, C. R. Acad. Sci. Paris 258 (1964), 4413-4416.

[2] M. K. Ahamad And SAlahuddin, Generalized strongly nonlinear implicit quasi-variational inequalities, J. Inequal. Appl. 2009, (2009), 1-16.

[3] M. K. AhAmAd And SAlahudDin, A stable perturbed algorithms for a new class of generalized nonlinear implicit quasi variational inclusions in Banach spaces, Adv. Pure Math. 2 (2) (2012), 139148.

[4] H. BREZIS, Operateurs maximaux monotones et semigroupes de contractions dans les espaces de Hilbert, North-Holland Publ. Co., Amsterdam and American Elsevier Publ. Co., New York 1973.

[5] T. CAI, Y. HAO, M. FU AND C. Y. JUNG, A system of generalized nonlinear variational inclusions with $(H, \eta)$-monotone operators, Nonlinear Funct. Anal. Appl. 24 (3) (2019), 627-637.

[6] M. C. FERRIS AND J. S. PANG, Engineering and economics applications of complementarity problems, SIAM Rev. 39 (1997), 669-713.

[7] A. FISCHER, Solution of monotone complementarity problems with locally Lipschitzian functions, Math. Prog. 76 (1997), 513-532.

[8] Salahuddin, On convergence rate of a splitting operator method for variational inclusions, Adv. Nonlinear Var. Inequal. 21 (1) (2018), 30-39.

[9] M. K. Ahmad And SAlahuddin, Perturbed three step approximation process with errors for a general implicit nonlinear variational inequalities, Int. J. Math. Math. Sci. (2006), 1-14.

[10] R. AHMAD, Q. H. ANS ARI AND S ALAHUDDIN, A perturbed Ishikawa iterative algorithm for general mixed multivalued mildly nonlinear variational inequalities, Adv. Nonlinear Var. Inequal. 3 (2) (2000), 53-64.

[11] I. K. ARgYros AND SALAhUdDIn, Generalized quasi split variational inequality problems involving relaxed cocoercive mappings, Adv. Nonlinear Var. Inequal. 18 (2) (2015), 40-47.

[12] E. CORMAN AND X. M. YUAN, A generalized proximal point algorithm and its convergence rate, SIAM J. Optim. 24 (4) (2014), 1614-1638.

[13] F. FACChinei And J. S. PAng, Finite-Dimensional Variational inequalities and Complementarity Problems, 1-2 1397, Springer, Berlin 2003.

[14] H. D. QI, Tikhonov regularization methods for variational inequality problems, J. Optim. Theory Appl. 102 (1999), 193-201.

[15] N. PARIKH And S. P. Boyd, Proximal algorithms, Found. Trend. Optim. 1 (2014), 127-239. 
[16] Z. L. GE, D. R. HAN, Q. Ni AND D. Z. W. WANG, An operator splitting method for monotone variational inequalities with a new perturbation strategy, Optim. Lett. 12 (2018), 103-122.

[17] D. R. HAN, W. XU AND H. YANG, An operator splitting for variational inequalities with partially unknown mappings, Numer. Math. 111 (2008), 207-237.

[18] S. Li, B. LIU, Y. ZHANG AND X. FENG, Iteration algorithm and convergence analysis for system of variational inequalities, Nonlinear Funct. Anal. Appl. 22 (5) (2017), 947-982.

[19] Z. L. GE, G. QIAN AND D. R. HAN, Global convergence of an inexact operator splitting method for monotone variational inequalities, J. Ind. Manag. Optim. 7 (2011), 1026-1026.

[20] B. S. HE, L. Z. LiAO AND S. L. WANG, Self-adaptive operator splitting methods for monotone variational inequalities, Numer. Math. 94 (2003), 715-737.

[21] D. R. HAN, Inexact operator splitting methods with self-adaptive strategy for variational inequalities problems, J. Optim. Theory Appl. 132 (2007), 227-243.

[22] B. C. EAVES, On the basic theorem of the complementarity, Math. Prog. 1 (1971), 68-75.

[23] T. ZHU AND Z. G. YU, A simple proof for some important properties of the projection mapping, Math. Inequal. Appl. 7 (2004), 453-456. 